\title{
PARA ALÉM DO DILEMA REDISTRIBUIÇÃO-RECONHECIMENTO: NANCY FRASER E A CONCEPÇÃO BIDIMENSIONAL DE JUSTIÇA
}

\author{
BEYOND THE DILEMMA REDISTRIBUTION-RECOGNITION: NANCY \\ FRASER AND THE TWO-DIMENSIONAL CONCEPTION OF JUSTICE
}

\author{
FRANCISCO JOZIVAN GUEDES DE LIMA ${ }^{1}$ \\ (Universidade Federal do Piauí, Brasil)
}

\begin{abstract}
RESUMO
Este artigo reconstrói a tese de Fraser acerca de uma justiça bidimensional apresentada como uma alternativa para o dilema redistribuição-reconhecimento. O modelo de justiça da redistribuição inspirado em Karl Marx defende a tese que as injustiças têm um fundo econômico e que só serão devidamente solucionadas a partir do enfrentamento das desigualdades sociais. O modelo de justiça do reconhecimento inspirado em Hegel e atualmente defendido por Honneth, acredita que as injustiças são gestadas a partir de questões concernentes a padrões culturais excludentes que negam status de reconhecimento de modo especial a negros, gays e mulheres. Para Nancy Fraser, os indivíduos sofrem injustiças ligadas a desigualdades sociais, econômicas e culturais. Uma teoria da justiça para obter o devido êxito deve confrontar elementos vinculados tanto à redistribuição quanto ao reconhecimento.
\end{abstract}

Palavras-chave: Fraser. Honneth. Justiça bidimensional. Reconhecimento. Redistribuição.

\begin{abstract}
This paper reconstructs the Fraser's thesis about a two-dimensional justice presented as an alternative to the redistribution-recognition dilemma. The justice model of redistribution inspired in Karl Marx defends the thesis that injustices have an economic background and will only be adequately solved from the confronting of the social inequalities. The justice model of recognition inspired by Hegel and currently defended by Honneth believes that injustices are gestated from issues concerning the cultural patterns that deny status of recognition especially to the blacks, gays and women. To Nancy Fraser, individuals suffer injustices connected to socialeconomics and cultural inequalities. A theory of justice to achieve the success must confront elements linked to both redistribution and recognition.

Keywords: Fraser. Honneth. Two-dimensional Justice. Recognition. Redistribution.
\end{abstract}

\section{Um diagnóstico acerca da justiça na era pós-socialista e a suposta diluição das lutas de classe}

O propósito precípuo deste tópico inicial consiste em colocar em relevo a premissa basilar da concepção dual de justiça de Fraser a partir da contraposição a um diagnóstico restritivo daquilo que ela cognomina de "era pós-socialista", a saber, que as injustiças não dizem mais respeito a questões de ordem socioeconômica, mas a questões de reconhecimento 
e de políticas voltadas para o tema da inclusão e da diferença como se a temática marxiana da luta de classes tivesse sido gradativamente obliterada e, consequentemente, tivesse perdido sua razão de ser na filosofia política contemporânea a partir mormente de meados do século XX.

No seu escrito "da redistribuição ao reconhecimento? Dilemas da justiça na era póssocialista", publicado em "Justice Interruptus: Critical reflections on the post-socialist condition", pela Routledge em 1997, Fraser inicia sua investigação frisando uma tese que atualmente vem ganhando força no cenário filosófico, a saber, que a luta por reconhecimento se tornou a forma paradigmática de conflito político no século $X X$. Trata-se de uma recondução do foco da justiça de questões distributivas para matérias concernentes ao tema da diferença e das políticas de reconhecimento (Politics of Recognition) que se interpõe como a nova pauta necessária. Esse deslocamento é perceptível por exemplo em Justice and Politics of Difference de Iris Marion Young quando ao criticar o reducionismo da teoria política ao paradigma distributivo de bens tece a seguinte afirmação:

\begin{abstract}
$\mathrm{Eu}$ argumento que em vez de se concentrar na distribuição, uma concepção de justiça deve começar com os conceitos de dominação e opressão. Tal mudança traz à tona questões da tomada de decisão, da divisão do trabalho e da cultura que se relacionam com a justiça social, porém frequentemente ignoradas nas discussões filosóficas. Ela também apresenta a importância das diferenças de grupos sociais na estruturação de relações sociais e opressão; tipicamente, as teorias filosóficas de justiça têm operado com uma ontologia social na qual não há espaço para um conceito de grupos sociais. Eu argumento que onde existem diferenças de grupos sociais e onde alguns grupos são privilegiados enquanto outros são oprimidos, a justiça social necessita explicitamente reconhecer e acompanhar a essas diferenças de grupos a fim de minar a opressão (YOUNG, 1990, p. 3)2.
\end{abstract}

Habermas em Direito e democracia (1997, p. 159) acompanha a crítica de Iris M. Young afirmando que "o paradigma do direito liberal e do Estado social cometem o mesmo erro, ou seja, entendem a constituição jurídica da liberdade como ‘distribuição' e a equiparam ao modelo da repartição igual de direitos adquiridos ou recebidos". Habermas e Young enquanto críticos do modelo restritamente distributivo defendem, portanto, de modo seguro que direitos não são coisas (bens), mas relações que se estabelecem no vínculo social em oposição ao uso da força e da arbitrariedade. A questão em jogo consiste na ruptura com um modelo de justiça restritivo distributivista que implica a figura de um Estado que confere verticalmente bens e direitos a indivíduos que os aguardam passivamente; tal corte demanda uma virada normativa no sentido que a partir daí os próprios cidadãos autonomamente devem ser capazes de estabelecer direitos a partir de suas relações intersubjetivas, de modo que o 
papel do Estado consiste apenas na juridificação da normatividade depreendida de tais relações. Esta nova configuração normativa centrada na autonomia política dos cidadãos e contrária à verticalização distributiva de direitos como bens pode ser encontrada na definição de "liberdade política" proposta por Forst em The Right to Justification quando afirma:

\begin{abstract}
Liberdade política é a forma de liberdade que as pessoas como cidadãos concedem umas às outras de modo recíproco e genérico. Não é 'o Estado' ou 'a comunidade' que distribui direitos e liberdades aos cidadãos; pelo contrário, os cidadãos mesmos são ao mesmo tempo os autores e os destinatários de reivindicações de liberdades (geralmente na forma de reivindicações de direito). Como cidadãos, pessoas são simultaneamente reivindicadores de liberdade (ou usuários de liberdade) e garantidores de liberdade (FORST, 2012, p. 126).
\end{abstract}

A mobilização pelo reconhecimento das diferenças vinculadas à nacionalidade, etnicidade, raça, gênero e sexualidade interpuseram-se para além dos interesses de classe; tal deslocamento pode ser apontado como uma característica fulcral da era pós-socialista: “A dominação cultural suplanta a exploração como a injustiça fundamental. E o reconhecimento cultural desloca a redistribuição socioeconômica como o remédio para injustiças e como o objetivo da luta política" (FRASER, 2001, p. 245).

O que há nessa conjuntura pós-socialista é aquilo que Habermas já diagnosticara em Technik und Wissenschaft als "Ideologie" (1968) como sendo o esvaziamento ou "latência" do conceito marxiano de luta de classes operacionalizado pela adesão e lealdade das massas aos apelos (promessa da qualidade de vida) do capitalismo que, como uma forma de desarticulação, procura evitar e pacificar os conflitos sociais:

O capitalismo estatalmente regulado, que surgiu de uma reação contra as ameaças
aos sistemas geradas pelo antagonismo aberto das classes, pacifica o conflito das
classes. O sistema do capitalismo tardio está a tal ponto determinado por uma
política de compensações que assegura a lealdade das massas dependentes do
trabalho, ou seja, por uma política de evitação do conflito [...]" (HABERMAS,
1987, p. 76).

Com a perda da centralidade da luta de classes - lutas tais concebidas dentro do ideário marxista do socialismo e do comunismo pensado enquanto doutrina de emancipação da classe proletária perante as opressões do sistema capitalista - as reivindicações por mudanças socioeconômicas e redistribuição de bens básicos (claims for redistribution) misturaram-se às reivindicações dos movimentos sociais por reconhecimento (claims for recognition). Destarte, as políticas de identidade e de reconhecimento paulatinamente sobrepuseram-se a políticas sociais, algo, por exemplo, cotidianamente perceptível quando se vê alguns se perguntar sobre o porquê da sociedade endossar lutas pelo reconhecimento de 
direitos homossexuais e não dar a mesma atenção e intensidade às lutas sociais objetivando a diminuição da pobreza e da fome no mundo: “[...] de forma crescente, reivindicações com base em identidades tendem a predominar, já que prospectos de redistribuição parecem retroceder. O resultado é um campo político complexo com pouca coerência programática" (FRASER, 2001, p. 248).

Pouca coerência programática porque lutas por reconhecimento acontecem em um mundo quase na sua totalidade marcado por desigualdades sociais e degradação das condições materiais de existência, seja na saúde, educação, alimentação, moradia, saneamento, lazer, expectativa de vida e taxas de mortalidade não ideais. Nesse sentido, focar apenas no reconhecimento em detrimento da redistribuição é algo de saída problemático, sobretudo devido à ambivalência em que muitos sofrem injustiças tanto socioeconômicas quanto no que diz respeito à negação do reconhecimento. Por isso, a tese de Fraser é que a justiça pressupõe tanto redistribuição quanto reconhecimento. A isso ela chama de "concepção dual ou bidimensional de justiça", algo frisado posteriormente em Redistribution or Recognition (2003, p. 9) escrito em parceria com Honneth: "esta é a minha tese geral: que a justiça hoje requer redistribuição e reconhecimento. Nenhum por si só é suficiente”.

\section{O dilema redistribuição-reconhecimento e o seu confrontamento a partir do hibridismo "coletividades ambivalentes"}

Neste tópico, a pesquisa tem como pretensão fundamental articular as bases da concepção bidimensional de justiça a partir daquilo que Fraser propõe como "coletividades ambivalentes", conceito segundo o qual os indivíduos sofrem injustiças tanto de ordem redistributiva quanto de ordem de reconhecimento, apostando, portanto, numa teoria que tenha diante de si claims for redistribution e claims for recognition, um ponto de fusão que pretende combater as exclusões ligadas a padrões culturais e socioeconômicos. Como pano de fundo das intenções está a necessidade de superação do dilema redistribuição-reconhecimento que implica na queda de braço entre concepções de justiça de matriz economicista versus aquelas de matriz culturalista, culturalista no sentido que veem os processos de exclusão de minorias como produtos de construções de padrões culturais intencionalmente forjados para cumprir com o objetivo do não-reconhecimento e do desrespeito de determinadas categorias e grupos sociais (negro, gay, mulher, etc.).

Nancy Fraser entende que há dois imaginários políticos contraproducentes e dilemáticos quando fechados e autorreferenciados em si mesmos: o socialista centrado nas 
categorias da redistribuição, exploração e interesse; e o do reconhecimento centrado nas categorias da dominação cultural, identidade e diferença ${ }^{4}$. O primeiro acredita que a injustiça é socioeconômica e concerne à exploração da força de trabalho, à marginalização e à privação de condições materiais de vida. Aqui aparecem teóricos igualitaristas como Marx e seu diagnóstico sobre a exploração capitalista, Rawls e a defesa da distribuição dos bens primários $^{5}$, Sen e a teoria das capacidades, e Dworkin com a defesa da igualdade de recursos. O modelo redistributivista acredita, portanto, que a raiz da injustiça cultural que leva a experiências malsucedidas de reconhecimento é consequência fundamentalmente da má distribuição de renda, da desigualdade de oportunidades e da escassez de bens sociais. O ponto chave de imersão revolucionária não seria, ipso facto, a acentuação das diferenças identitárias como assim pretende o modelo do reconhecimento, mas, pelo contrário, a abolição das diferenças.

A justiça pensada em termos redistributivos no parecer de Young é restritiva e problemática porque "[...] ela tende a concentrar-se pensando sobre justiça social em termos de alocação de bens materiais como coisas, recursos, riqueza, ou em termos de distribuição de posições sociais, especialmente trabalho. Este foco tende a ignorar a estrutura social e o contexto institucional que frequentemente ajudam a determinar padrões distributivos" (YOUNG, 1990, p. 15) ${ }^{6}$. O ideal de acordo com Young é que - indo na contramão da proposta redistributiva - as injustiças sejam pensadas a partir de questões ligadas ao racismo e ao sexismo, de modo que as categorias centrais em jogo sejam "opressão" e "dominação".

O segundo imaginário político crê que a injustiça não tem especificamente a ver com a divisão social do trabalho ou propriamente com as desigualdades sociais, mas que ela é cultural ou simbólica e, portanto, está arraigada nos padrões sociais de representação que levam ao desrespeito. Ou seja, os indivíduos são socialmente marginalizados porque não são devidamente reconhecidos, de modo que a exclusão social é produto do não-reconhecimento. Aqui irrompem os nomes de Charles Taylor para quem o não-reconhecimento é uma forma de opressão, e Honneth para quem o desrespeito é tomado como uma agressão à integridade. Em Politics of Recognition pode-se encontrar a seguinte passagem onde Taylor é claro em sua afirmação acerca da relação entre identidade e reconhecimento e os efeitos sociais e psicológicos que tal relação pode causar quando é estabelecida de um modo precário. 
desprezível de si. Não-reconhecimento ou desconhecimento pode causar danos que podem ser uma forma de opressão, aprisionando alguém num modo de ser falso, distorcido e reduzido (TAYLOR, 1992, p. 25) ${ }^{7}$.

Taylor enxerga uma dificuldade de implementação de políticas do reconhecimento no próprio Estado democrático de direito que ele vê como um garantidor das proteções de direitos individuais incompatibilizando destarte a proteção de direitos relativos a grupos sociais, algo que na opinião de Habermas é equivocado, pois, conforme expressa em $A$ Inclusão do Outro, num Estado democrático de direito sério não tem sentido contrapor direitos subjetivos a direitos coletivos e sociais, haja vista a premissa da própria teoria do reconhecimento que os direitos subjetivos de uma dada identidade são formatados de modo intersubjetivo e não mediante um experimento mental monológico.

\begin{abstract}
Quando tomarmos a sério essa concatenação interna entre o Estado de direito e a democracia, porém, ficará claro que o sistema dos direitos não fecha os olhos nem para as condições de vida sociais desiguais, nem muito menos para as diferenças culturais. [...]. Sob essa premissa, uma teoria dos direitos entendida de maneira correta vem exigir exatamente a política de reconhecimento que preserva a integridade do indivíduo, inclusive nos contextos vitais que conformam sua identidade. [...]. E sem os movimentos sociais e sem lutas políticas, vale dizer, tal realização teria poucas chances de acontecer (HABERMAS, 2002, p. 235).
\end{abstract}

Honneth por sua vez implementa sua teoria do reconhecimento social apoiando-se metodologicamente na crítica às teorias procedimentalistas da justiça e tomando como ponto de ancoragem a intuição de Hegel nos Escritos da juventude acerca dos processos dialéticos de reconhecimento. No seu prisma, as teorias da justiça conjecturadas mediante o procedimentalismo como é o caso de Rawls (posição original), são fadadas a colapsar suas bases normativas porque as normas são depreendidas verticalmente sem as incursões dos agentes sociais que lutam por reconhecimento em suas atividades cotidianas; elas solapam porque se embasam numa concepção de self e de autonomia a partir de um polo excessivamente solipsista e, por isso, incorrem em patologia social. Honneth em The Fabric of Justice (2015b, p. 166) entende que a autonomia é fruto de interrelações; ela é uma grandeza intersubjetiva e não um êxito monológico.

A metodologia honnethiana para empreender seu projeto crítico-reconstrutivo da liberdade social tem como uma das fontes de inspiração, como dito anteriormente, Hegel, sobretudo, o jovem filósofo de Stuttgart - anterior àquele da Fenomenologia do Espírito (1807) - que prezara por um projeto de reconhecimento em termos éticos e intersubjetivos a partir do protagonismo do sujeito, ao invés do protagonismo metafísico do espírito absoluto. A eticidade ${ }^{8}$ proposta pelo Hegel "maduro", de modo especial aquela desenvolvida na 
Philosophie des Rechts (1820), no parecer de Honneth ainda não alcança devidamente a eticidade democrática porque em última instância o seu processo é conduzido pelo espírito absoluto manifestado na arte, na religião e na filosofia, "espírito" tal que Feuerbach nas suas Teses provisórias para a reforma da filosofia (1988, p. 22) categorizou como sendo "o espírito defunto da teologia" ressuscitado por Hegel.

Rainer Forst (2010, p. 327) acompanha a conjectura de Honneth afirmando que "por meio desse passo de substancialização do espírito objetivo e da mediação completa da subjetividade e objetividade no espírito absoluto, Hegel 'reprime' a ideia de uma constituição intersubjetiva, aberta e interminável da "consciência universal"”. É por isso que Honneth (2003) entende que Hegel ao se aportar na ideia de espírito absoluto em detrimento da dinâmica social das lutas por reconhecimento recai num "modelo substancialista de eticidade". A justiça tem a ver com dinâmicas sociais de luta por reconhecimento, de modo que não é preciso alterar status metafísico algum, mas sim os padrões culturais de comportamento gestados concretamente na história de cada comunidade ética.

Um dos artifícios usados pelos defensores do imaginário político pró-reconhecimento para legitimar a tese que as injustiças são operacionalizadas a partir da instituição de padrões culturais excludentes, é o exemplo da "sexualidade menosprezada"; os desrespeitos a homossexuais no modelo do reconhecimento são tomados como diferenciações sociais cujas origens não concernem à redistribuição socioeconômica, haja vista tais desrespeitos permearem todas as classes, mas concernem ao heterossexismo convertido cotidianamente em práticas homofóbicas. Como avalia Fraser (2001, p. 257-258), “ao terem sua sexualidade desacreditada, os homossexuais estão sujeitos à vergonha, molestação, discriminação e violência, enquanto lhes são negados direitos legais e proteção igual - todas as negações fundamentais de reconhecimento".

Aqui volta à cena Young com sua defesa de uma justiça social em prol da valorização das dinâmicas de reconhecimento e da inclusão das diferenças e que, consequentemente, supere os limites do modelo redistributivo. A inclusão e o enfrentamento da opressão, dominação e do não-reconhecimento de categorias e grupos sociais excluídos, pressupõem o enfretamento daquilo que ela em Justice and Politics of Difference ao tratar no capítulo VII sobre o tema da "ação afirmativa" identifica como o "mito do mérito", mito no sentido que a métrica embasada na imparcialidade e numa posição original de igualdade é impossível, haja vista o enraizamento do indivíduo em circunstâncias sociais desiguais ser um dado preliminar e ineliminável. 
O ideal da distribuição meritocrática de posições é uma instância do ideal da imparcialidade. Critérios do mérito supõem que há medidas e fatores objetivos de competência independentes de atributos culturais e normativos. Mas eu argumento que não há tais medidas; alocação de funções é inevitavelmente política no sentido que ela envolve valores e normas específicas que não podem ser separadas de questões de competência técnica (YOUNG, 1999, p. 12) ${ }^{9}$.

A autora depreende que para a meritocracia de fato funcionar seria necessário contar com algo impossível, a saber, critérios normativos e culturais neutros isentos de arbitrariedades e injustiças no processo de equalização.

Para o princípio do mérito ser aplicado, deve ser possível identificar, mensurar, comparar e classificar o desempenho individual de tarefas relacionadas com as funções utilizando critérios que são normativamente e culturalmente neutros. Entretanto, para a maioria das funções, isto não é possível, e a maioria dos critérios de avaliação utilizados em nossa sociedade, incluindo as credenciais educacionais e testes padronizados, têm conteúdo normativo e cultural. Desse modo, não existem mensuras imparciais, científicas, valor-neutro do mérito (YOUNG, 1990, p. 193) ${ }^{10}$.

Como uma síntese de ambos os modelos pode-se dizer o seguinte: os partidários do modelo redistributivo propõem a redistribuição de renda, reorganização da divisão do trabalho e a sujeição dos investimentos à tomada de decisão democrática como remédios necessários para combater as injustiças socioeconômicas. Aqui está em jogo o redimensionamento da economia política. Já os partidários do espectro do reconhecimento cravam a tese que a injustiça é simbólico-cultural e que o remédio adequado para curar as patologias consiste na reavaliação das identidades desrespeitadas, na valoração da diversidade cultural (multiculturalismo) e na correção geral dos padrões de representação de individualidades marginalizadas (o negro, o gay, a mulher, etc.). "Embora esses remédios sejam diferentes entre si, devo referir-me, daqui para frente, a todo esse grupo pelo termo "reconhecimento"" (FRASER, 2001, p. 252).

A tese de Fraser pressupõe que ambos os imaginários políticos supracitados sejam pensados e ressignificados de um modo articulado:

Claro que essa distinção entre injustiça econômica e injustiça cultural é analítica. $\mathrm{Na}$ prática, ambas estão interligadas. [...] longe de ocuparem esferas separadas, injustiça econômica e injustiça cultural normalmente estão imbricadas, dialeticamente, reforçando-se mutuamente. Normas culturais enviesadas de forma injusta contra alguns são institucionalizadas no Estado e na economia, enquanto as desvantagens econômicas impedem participação igual na fabricação da cultura em esferas públicas e no cotidiano. O resultado é frequentemente um ciclo vicioso de subordinação cultural e econômica (FRASER, 2001, p. 251).

Essa dicotomia supracitada tanto no que concerne à identificação da injustiça quanto ao seu remédio, culmina numa relação dilemática entre redistribuição e reconhecimento: de 
um lado, o modelo redistributivista reivindica a supressão das diferenças; de outro, o modelo do reconhecimento reivindica a afirmação das diferenças. Para esclarecer esse dilema, Fraser recorre àquilo que designa de "coletividades ambivalentes" ou "modelos híbridos", situações nas quais algumas categorias sofrem injustiças derivativas tanto dos problemas de redistribuição quanto de problemas advindos do não-reconhecimento, como é o caso da injustiça de gênero e da injustiça racial.

Essas coletividades são 'ambivalentes'. São diferenciadas como coletividades em virtude tanto da estrutura político-econômica como da cultural-valorativa. Então, quando oprimidos ou subordinadas, sofrem injustiças ligadas à economia política e à cultura simultaneamente. [...]. Nesse caso, nem remédios redistributivos nem de reconhecimento isoladamente são suficientes. Coletividades ambivalentes precisam de ambos (FRASER, 2001, p. 259).

No que diz respeito à ambivalência de gênero, Fraser usa como exemplo a exclusão androcêntrica da mulher. Do ponto de vista redistributivo e, ipso facto, socioeconômico, na divisão de trabalho à mulher coube a função do trabalho doméstico não assalariado, quase que vocacional ou escravo, algo que repercute ainda hoje na disparidade salarial entre trabalho masculino e feminino. Em Unruly Pratices (p. 148), especificamente a partir do capítulo em que trata da relação entre as mulheres e as políticas de bem-estar social, Fraser suscita o debate em torno da exclusão feminina a partir de uma "divisão sexual do trabalho" que delega à mulher a tarefa e a responsabilidade de cuidar daqueles incapazes de cuidar de si mesmos, um trabalho realizado sem direitos previdenciários ou mesmo sem a mínima remuneração como se tal atividade fosse parte constitutiva do ser mulher. Do ponto de vista do fator econômico, a dita exclusão é gerada por um sistema pautado em padrões sociais de dominação e subordinação legitimando desta forma o diagnóstico marxiano acerca da lógica de comportamento das sociedades capitalistas.

Claro que as sociedades capitalistas tardias não são simplesmente pluralistas. Pelo contrário, elas são estratificadas, diferenciadas em grupos sociais com status de desigualdade, poder e acesso a recursos permeados por eixos difusos de desigualdades em função de critérios de classe, gênero, raça, etnicidade e idade (FRASER, 1989, p. 165) ${ }^{11}$.

Entretanto, esse déficit não se deve somente à divisão social do trabalho, mas à negação do devido reconhecimento às mulheres. É, nesse sentido, uma diferenciação perversa forjada culturalmente por civilizações androcêntricas através da construção autoritária de normas visando depreciar a figura feminina, algo que se solidificou com o sexismo cultural, situação na qual a mulher é reificada (FRASER, 2001, p. 260). Ou seja, a situação de 
inferioridade da mulher é construída a partir de condicionamentos econômicos e culturais que estão imbricados entre si há séculos. Não há apenas isoladamente o movedor econômico ou cultural e ideológico como o culpado pela situação; as injustiças são produzidas por fatores intercruzados, e daí a dificuldade em dirimi-los já que as estratégias comumente focam apenas em um fator em detrimento de outro perdendo, desta forma, a noção de conjunto no enfrentamento de injustiças.

No que diz respeito à ambivalência racial, Fraser cita o caso da exclusão dos negros que, como o caso da depreciação feminina, tem motivos socioeconômicos / redistributivos e motivos ligados ao não-reconhecimento e, por isso, vertentes culturais e ideológicas ainda estereotipadas e arraigadas na sociedade atual. Argumenta Fraser (2001, p. 263): “O aspecto central do racismo é o eurocentrismo: a construção autoritativa de normas que privilegiam traços associados com o fato de ser branco. Ao lado disso está o racismo cultural: a desvalorização e depreciação de coisas tidas como negras [...]”. Isso na prática constata-se em ideias controversas de que o negro é superior fisicamente, porém intelectualmente inferior ao branco, que os negros são criminosos, dentre outros jargões preconceituosos.

\section{Considerações finais: a cura das patologias econômico-culturais a partir de remédios "afirmativos" e "transformativos"}

Posta a imprescindibilidade da articulação dos modelos da redistribuição e do reconhecimento enquanto modelos duais ou bidimensionais de justiça, Fraser (2001, p. 280) mesmo reconhecendo que não há qualquer jogada teórica que permita a completa dissolução ou resolução do dilema - apresenta uma possível saída para a cura das patologias advindas das injustiças socioeconômicas e culturais a partir daquilo que ela designa como redistribuição e reconhecimento enquanto "remédios" "afirmativos" e "transformativos".

\footnotetext{
Por remédios afirmativos para injustiça entendem-se remédios voltados para a correção de resultados indesejáveis de arranjos sociais sem perturbar o arcabouço que os gera. Por remédios transformativos, em contraste, entendem-se remédios orientados para a correção de resultados indesejáveis precisamente pela reestruturação do arcabouço genérico que os produz (FRASER, 2001, p. 265-266).
}

Os remédios afirmativos ${ }^{12}$ propõem correções, visam a afirmar as diferenças, sem, entretanto, modificar e descontruir o status quo que gera a injustiça redistributiva ou de reconhecimento. Ela é, assim, uma espécie de arranjo e paliativo. Paradoxalmente, os remédios transformativos visam a descontruir o status quo que gera a injustiça. 
No caso do problema racial, remédios afirmativos apenas forneceriam "cotas raciais" ou outra medida, mas não se proporiam a erradicar o racismo em sua gênese como fariam os remédios transformativos. Fraser (2001, p. 266) cita como exemplo de afirmação o multiculturalismo, pois este aponta para as diferenças, mas não tenciona soluções robustas contra o racismo. No caso da homofobia, remédios afirmativos parariam na reivindicação de políticas de identidade gay, mas não alcançariam o status reivindicatório dos remédios transformativos que visariam a desconstruir a dicotomia homo-hétero (FRASER, 2001, p. 267).

No que diz respeito à injustiça econômica, remédios redistributivos afirmativos fariam a redistribuição de recursos ou transferência de renda via Estado de bem-estar social sem, entretanto, afetar a estrutura político-econômica que mantém a desigualdade sempre atualizada. "Longe de abolir as diferenças de classe, esses remédios afirmativos as suportam e modelam” (FRASER, 2001, p. 269). Já os remédios redistributivos transformativos tentariam ao máximo minar as diferenças de classe, por isso tem um padrão mais socialista. O que há de comum entre um e outro é que, como o afirmativo, o transformativo também pressupõe uma concepção universalista e deontológico do valor moral igual das pessoas para, assim, fazer suas reivindicações (FRASER, 2001, p. 271).

Para Fraser, os remédios mais promissores para combater as patologias das injustiças socioeconômicas e do reconhecimento são os transformativos, pois no que diz respeito à redistribuição, visam a reestruturar as relações sociais e eliminam diferenciações de grupos a partir da igualdade social radical. No que diz respeito ao reconhecimento, indo além do multiculturalismo dominante, descontroem as bases mantenedoras do racismo, do androcentrismo, do sexismo, na medida em que quebram o binômio branco/negro, homem/mulher, homo/hétero.

Prima facie, o que se pode concluir - recorrendo-se às palavras da própria Fraser (2001, p. 267) - é que "o cenário que mais escapa ao dilema redistribuição/reconhecimento é o socialismo na economia e a desconstrução na cultura", porque ambos não simplesmente se conformam ao status quo gerador de injustiças através de arranjos e paliativos, mas, pelo contrário, pretendem transformá-lo. A questão que persiste não suficientemente confrontada e respondida pela autora é como em nível de implementação prática uma concepção dual de justiça pode afetar as injustiças na sua origem com pretensões - conforme ela mesma conjectura - socializantes dos meios de produção e, concomitantemente, com pretensões de desconstrução de padrões culturais mantenedores do racismo, androcentrismo e do sexismo 
em seu cerne ao invés de paliativos em termos de "remédios afirmativos", tão vigentes em políticas públicas de Estados atualmente e sobre os quais - os remédios afirmativos - a autora mantém sua suspeição.

Portanto, trata-se enquanto pretensão teórica, de uma proposta sem sombra de dúvida incisiva e arrojada, sobretudo quando se evoca a necessidade de superação do dilema redistribuição-reconhecimento sob o argumento que os indivíduos sofrem injustiças tanto econômicas quanto culturais, todavia, em nível de efetividade parece persistir um déficit fenomenológico no sentido de uma carência de um exame sobre a viabilidade de concretização do formato bidimensional de justiça que procura afetar na fonte as injustiças vinculadas à redistribuição de bens e a políticas do reconhecimento. 


\section{Notas:}

1 Doutor em Filosofia pela Pontifícia Universidade Católica do Rio Grande do Sul (PUCRS). Professor no Programa de Pós-Graduação e na Graduação do Departamento de Filosofia da Universidade Federal do Piauí (UFPI), Teresina, PI, Brasil. e-mail: jozivan2008guedes@gmail.com

2 "I argue that instead of focusing on distribution, a conception of justice should begin with the concepts of domination and oppression. Such a shift brings out issues of decision making, division of labor, and culture that bear on social justice but are often ignored in philosophical discussions. It also exhibits the importance of social group differences in structuring social relations and oppression; typically, philosophical theories of justice have operated with a social ontology that has no room for a concept of social groups. I argue that where social group differences exist and some groups are privileged while others are oppressed, social justice requires explicit acknowledging and attending to those group differences in order to undermine oppression". Tradução nossa. (YOUNG, 1990, p. 3).

3 Political liberty is the form of liberty that persons as citizens grant each other reciprocally and generally. It is not "the state" or "the community" that "distributes" rights and liberties to citizens; rather, the citizens themselves are at the same time the authors and the addressees of claims to liberties (usually in the form of rights claims). As citizens, persons are both freedom-claimers (or freedom-users) and freedom-grantors. Tradução nossa. (FORST, 2012, p. 126).

${ }^{4}$ Semelhante a Fraser, Habermas identifica tal polarização, porém ressignificada nos seguintes termos: "Liberais da grandeza de Rawls ou Dworkin propugnam por uma ordem jurídica eticamente neutra que deve assegurar chances iguais a todos, de modo que cada um possa orientar-se por uma concepção própria do que seja bom. Em face disto, comunitaristas como Taylor e Walzer contestam que haja neutralidade ética no direito e permitem-se, portanto, esperar também do Estado de direito a fomentação ativa de determinadas concepções do bem viver, caso isso se faça necessário". (HABERMAS, 2002, p. 233). ${ }^{5}$ Rawls entende que o "mínimo existencial”, isto é, o conjunto de bens básicos necessários à manutenção da vida
deve ser implementado pelo Estado, inclusive através de salário-família aos mais necessitados: Isso se consegue
por meio da fiscalização de empresas e associações privadas e pela prevenção do estabelecimento de medidas
monopolizantes e de barreiras que dificultem o acesso às posições mais procuradas. Por último, o governo
garante o mínimo social, seja através de um salário-família e de subvenções especiais em casos de doença e
desemprego, seja mais sistematicamente por meio de dispositivos tais como um suplemento gradual de renda (o
chamado imposto de renda negativo). Cf. (RAWLS, 2002, § 43, p. 304).

6 " 6 [...] it tends to focus thinking about social justice on the allocation of material goods such as things, resources, income, and wealth, or on the distribution of social positions, especially jobs. This focus tends to ignore the social structure and institutional context that often help determine distributive patterns". Tradução nossa. (YOUNG, 1990, p. 15).

7 "The thesis is that our identity is partly shaped by recognition or its absence, often by the misrecognition of others, and so a person or group of people can suffer real damage, real distortion, if the people or society around them mirror back to them a confining or demeaning or contemptible picture of themselves. Nonrecognition or misrecognition can inflict harm, can be a form of oppression, imprisoning someone in a false, distorted, and reduced mode of being”. Tradução nossa. (TAYLOR, 1992, p. 25).

${ }^{8}$ É possível depreender elementos metafísicos fortes já dentro da filosofia do jovem Hegel quando em $O$ sistema da vida ética (1802) vincula o ético ao absoluto: "a vida ética é, por conseguinte, determinada de um modo tal que o indivíduo seja igual ao conceito absoluto, que a sua consciência empírica seja uma só coisa com a consciência absoluta". Habermas em Pensamento pós-metafísico (p. 41) considera que a filosofia hegeliana no seu todo ainda ficou presa a um modelo metafísico autorreferenciado voltado para a redução da multiplicidade a uma unidade totalizante.

${ }^{9}$ The ideal of merit distribution of positions is an instance of the ideal of impartiality. Criteria of merit assume that there are objective measures and predictors of technical work performance independent of cultural and normative attributes. But I argue that no such measures exist; job allocation is inevitably political in the sense 
that it involves specific values and norms which cannot be separated from issues of technical competence. Tradução nossa. (YOUNG, 1990, p. 12).

10 For the merit principle to apply it must be possible to identify, measure, compare, and rank individual performance of job-related tasks using criteria that are normatively and culturally neutral. For most jobs, however, this not possible, and most criteria of evaluation used in our society, including educational credentials and standardized testing, have normative and cultural content. Since impartial, value-neutral, scientific measures of merit do not exist. Tradução nossa. (YOUNG, 1990, p. 193).

11 "Of course, late capitalist societies are not simply pluralist. Rather, they are stratified, differentiated into social groups with unequal status, power, and access to resources, traversed by pervasive axes of inequality along lines of class, gender, race, ethnicity, and age”. Tradução nossa. (FRASER, 1989, p. 165).

12 No seu livro Justice (2009), Sandel dedica um capítulo ao tema da ação afirmativa demonstrando a sua complexidade, sobretudo quando ao invés de reparar injustiças ela acaba por criá-las. Para exemplificar, cita o caso de Cheryl Hopwood, uma aspirante ao curso de Direito da Universidade do Texas que pautava a admissão de novos alunos mediante uma política de ação afirmativa para minorias raciais e étnicas. Hopwood obtivera um índice de aprovação, porém no cômputo geral não conseguira a vaga porque outros alunos inseridos na cota de $15 \%$ das vagas já tinham obtido êxito com provas com padrões mais acessíveis. Sentindo-se injustiçada, ela recorrera aos tribunais alegando que a métrica era injusta e excludente, pois outros com notas mais baixas tinham conquistado uma vaga que, se num mesmo nível seletivo, seria naturalmente sua, haja vista a pontuação obtida. Alegara também que neste caso ela, branca e de família não abastada, era minoria e que não devia ser culpada por injustiças feitas a negros e a hispânicos em tempos passados e por outras gerações. No fundo da sua argumentação estava a ideia que estavam tentando reparar uma injustiça criando outra. A resposta da Universidade foi que sua missão institucional consistia em incluir a diversidade racial e étnica com vistas à inserção profissional de camadas comumente marginalizadas. Acerca deste problema, cf. (SANDEL, 2014, p. 209). 


\section{Referências bibliográficas:}

FEUERBACH, Ludwig Andreas. Teses provisórias para a reforma da filosofia. In: Princípios da filosofia do futuro e outros escritos. Trad. Artur Morão. Lisboa: Edições 70, 1988.

FORST, Rainer. Contextos da justiça: filosofia política para além de liberalismo e comunitarismo. Trad. Denilson Luís Werle. São Paulo: Boitempo, 2010.

. The Right of Justification: Elements of a Constructivist Theory of Justice. Translated by Jeffrey Flynn. New York: Columbia University Press, 2012.

FRASER, Nancy. "Da redistribuição ao reconhecimento? Dilemas da justiça na era póssocialista". In: SOUZA, Jessé (Org.). Democracia hoje: novos desafios para a teoria democrática contemporânea. Brasília: Editora Universidade de Brasília, 2001.

. Unruly Practices: Power, Discourse, and Gender in Contemporary Social Theory. Minneapolis: University of Minnesota Press, 1989.

FRASER, Nancy; HONNETH, Axel. Redistribution or recognition? A political-philosophical exchange. Translated by Joel Golb, James Ingram, and Christiane Wilke. New York: Verso, 2003.

HABERMAS, Jürgen. A inclusão do outro: estudos de teoria política. Trad. George Sperber e Paulo A. Soethe. São Paulo: Loyola, 2002.

. Direito e democracia: entre facticidade e validade, v. 2. Trad. Flávio Beno Siebeneichler. Rio de Janeiro: Tempo Brasileiro, 1997.

- Pensamento pós-metafísico: estudos filosóficos. Trad. Flávio Beno

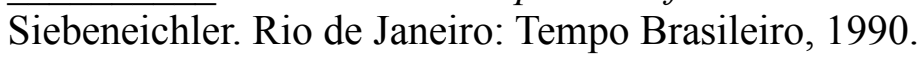
1987.

. Técnica e ciência como “Ideologia”. Trad. Artur Morão. Lisboa: Edições 70,

HEGEL, Georg Wilhelm Friedrich. O sistema da vida ética. Trad. Artur Morão. Lisboa: Edições 70, 1991.

HONNETH, Axel. Luta por reconhecimento: a gramática moral dos conflitos sociais. Trad. Luiz Repa. São Paulo: Ed. 34, 2003.

. "The fabric of justice: on the limits of proceduralism". In. OLIVEIRA, Nythamar; HRUBEC, Marek; SOBOTTKA, Emil; SAAVEDRA, Giovani (Eds.). Justice and Recognition: On Axel Honneth and Critical Theory. Porto Alegre / Prague: PUCRS / Filosofia, 2015b, p. 155-180.

RAWLS, John. Uma teoria da justiça. Trad. Almiro Pisseta e Lenita M. R. Esteves. São Paulo: Martins Fontes, 2002. 
SANDEL, Michael J. Justiça - o que é fazer a coisa certa. 16 a ed. Trad. Heloisa Matias e Maria Alice Máximo. Rio de Janeiro: Civilização Brasileira, 2014.

TAYLOR, Charles. "The Politics of Recognition". In: Multiculturalism and The Politics of Recognition. Edited by Amy Gutmann. Princeton, NJ: Princeton University Press, 1992.

YOUNG, Iris Marion. Justice and Politics of Difference. Princeton, New Jersey: Princeton University Press, 1990. 